\title{
Frequency distributions of the mixing height over an urban area from SODAR data
}

\author{
STEFAN EMEIS $^{1 *}$ and MATTHIAS TÜRK ${ }^{2}$ \\ ${ }^{1}$ Institute for Meteorology and Climate Research, Forschungszentrum Karlsruhe GmbH, Germany \\ ${ }^{2}$ Institute for Meteorology, University of Freiburg, Germany
}

(Manuscript received December 14, 2003; in revised form March 8, 2004; accepted March 29, 2004)

\begin{abstract}
The height of the mixing-layer (MLH) is an important parameter in the assessment of the dilution of primarily emitted or secondarily formed air pollutants in the atmospheric boundary-layer. A continuous measurement of MLH is possible only by remote sensing. Here, 17 months of SODAR data have been analysed automatically to derive the MLH over the city of Hannover in Northern Germany. In contrast to earlier studies the MLH has been determined from vertical profiles of the acoustic backscatter intensity and from the variance of the vertical velocity component. The results are presented in form of monthly frequency distributions and mean daily courses of MLH. These statistical evaluations of MLH show a clear annual course and interannual variability. The study shows the possibility to derive meaningful climatological information from long-term SODAR measurements for air quality issues.

\section{Zusammenfassung}

Die Höhe der Mischungsschicht (MLH) ist ein wichtiger Parameter bei der Abschätzung der Verdünnung primär emittierter oder sekundär gebildeter Luftschadstoffe in der atmosphärischen Grenzschicht. Eine kontinuierliche Messung der MLH ist nur mit Fernerkundungsverfahren möglich. Hier sind SODAR-Daten aus 17 Monaten Messungen in Hannover mit einem automatisierten Verfahren ausgewertet worden. Im Gegensatz zu früheren Untersuchungen wird die MLH hier aus der gemeinsamen Analyse von akustischen Rückstreuprofilen und Profilen der Varianz der Vertikalgeschwindigkeit bestimmt. Die Ergebnisse werden in Form von monatlich gemittelten Häufigkeitsverteilungen und mittleren Tagesgängen der MLH präsentiert. Die statistische Auswertung der MLH zeigt einen klaren Jahresgang und die interannuelle Variabilität dieser Größe. Diese Untersuchung zeigt eine Möglichkeit auf, wie für Fragen der Luftqualität verwertbare klimatologische Informationen aus langfristigen SODAR-Messungen gewonnen werden können.
\end{abstract}

\section{Introduction}

In order to run numerical and physical models that simulate urban air quality a priori information on vertical profiles of wind, temperature, moisture, and other atmospheric constituents is necessary to prescribe the initial and boundary values. A posteriori this information is needed to check the results. Likewise this information is needed to estimate the dilution of pollutants emitted or formed secondarily near the surface because temperature inversions and layers of low turbulence form a potential barrier for vertical dispersion. Similarly the information on vertical dispersion and dilution of particulate matter is important when inverting optical thicknesses measured from satellites into surface pollutant concentrations (DANDOU et al., 2002; SCHÄFER et al., 2002). The vertically resolved information is required at least for the vertical extend of the layer that is in direct contact with the surface. This layer is usually identified as

\footnotetext{
${ }^{*}$ Corresponding author: Stefan Emeis, Institut für Meteorologie und Klimaforschung, Atmosphärische Umweltforschung (IMK-IFU), Forschungszentrum Karlsruhe $\mathrm{GmbH}$, Kreuzeckbahnstr. 19, 82467 Garmisch-Partenkirchen, Germany, e-mail: stefan.emeis@imk.fzk.de
}

the mixing-layer. The thermal stability and the height of the mixing-layer (MLH) exhibit a clear diurnal course, mainly driven by the radiation balance of the underlying surface. Its vertical extend varies between less than 100 $\mathrm{m}$ in very calm and clear nights and more than $2000 \mathrm{~m}$ with stormy weather or on clear and hot summer days. A dense data coverage on MLH can only be yielded by remote sensing techniques.

The definition and the methods of detection of the MLH have been discussed broadly in BEYRICH (1997) and SEIBERT et al. (2000). The derivation of MLH from radiosonde temperature profile data is the oldest method. Starting with HOLZWORTH (1964) various schemes have been proposed. An actual example for the application of his method, the monitoring of the annual variation of MLH from daily late-afternoon radiosonde ascents is presented in FREEDMAN et al. (2001). They find the maximum MLH in the Northeastern US in late spring just before the growing season starts. MLH frequency distributions for five months for Mexico City from two soundings per day can be found in SALCIDO et al. (2003). HolzWORTH's method is only appropriate to find MLH for the time of the sounding but is 
not able to detect the diurnal course of MLH. Further, the method is limited mainly to convective conditions. A critical discussion of his approach can be found in LOKOSHCHENKO (2002).

Profiling the mixing layer by acoustic remote sensing with a SODAR is an appropriate method because these instruments have a small lower detection height (some tens of metres) and a high vertical resolution (in the order of ten to thirty metres). BEYRICH (1997) has presented a critical review of MLH estimation from SODAR data. In addition to his study a comparison of SODAR data to radiosonde data or the intercomparison to other remote sensing techniques may help to identify the relevant structures in the acoustic backscatter from the atmosphere. LOKOSHCHENKO (2002) has recently compared MLH from SODAR and radiosonde data using Holzworth's method, which revealed the difficulties of determining and comparing MLH from these two types of data. A likewise study has been made by KEDER (1999) who compared radiosonde data evaluated following MYRICK et al. (1994) with the built-in MLH-determining routine of a commercially available SODAR. Here the comparison was even more disappointing, but mainly due to errors in the automatic routine supplied by the SODAR manufacturer. COULTER (1979) has compared the temperature profile method with LIDAR and SODAR measurements. In early morning and late afternoon hours the LIDAR data systematically yielded higher convective boundary-layer (CBL) tops than the SODAR data. The data from both remote sensing methods always delivered higher CBL tops than the evaluation of the temperature profile. Following Coulter (1979), this is because particulates mix to larger heights than the top of the adiabatic temperature profile, while temperature fluctuations exhibit an increase in the entrainment zone above the top of the adiabatic temperature profile but below the maximum height of particulate mixing. DEVARA et al. (1995) have compared a LIDAR and a SODAR in a study on the nocturnal stable boundary-layer. They found a principal agreement in the results. BEYRICH and GÖRSDORF (1995) have used two instruments, a SODAR and a wind profiler simultaneously for five weeks in order to determine the MLH. They found that on days with the development of a CBL both instruments yielded comparable results during the morning hours.

Nearly all of the above mentioned remote sensing studies have performed analyses of short measurement campaigns. The only long-term evaluations were presented by MAUGHAN et al. (1982) who investigated one year of data and by LOKOSCHENKO (2002) who had 10 years of SODAR data available. In addition Lokoschenko's study is the only one available for an urban area. In the present paper we will evaluate MLH from SODAR data from a two-year cam- paign in an urban area. The method is closely related to the one of BEYRICH (1997), but in contrast to him, LOKOSCHENKO (2002), and other earlier studies acoustic backscatter intensity and the variance of the vertical velocity component are used simultaneously when analysing the profile data. The SODAR used here delivers very reliable values for the variance of the vertical velocity component. The MLH-deriving method has successfully been tested in a remote sensing intercomparison experiment (EMEIS et al., 2004) between this SODAR, a RASS (a combination of a windprofiler with a SODAR that measures temperature profiles) and a ceilometer (a small specially designed LIDAR that measures optical backscatter from aerosols).

\section{Method}

The METEK DSD3x7 mono-static Doppler SODAR (REITEBUCH and EMEIS, 1998) has three antennas with seven sound transducers (i.e. a device that serves both as a loudspeaker and as a microphone, depending on the phase of the measurement cycle) each, working at $1674 \mathrm{~Hz}$. The instrument is optimised for long-range detection up to $1300 \mathrm{~m}$ above ground in ideal conditions without external noise sources. It returns the acoustic backscatter intensity, the three components of the wind, and the variance of the vertical velocity component $\sigma_{w}$ together with an estimate of the signal-to-noise ratio and an error code. In mono-static acoustic remote sensing the backscatter intensity depends only on temperature gradients caused by turbulent fluctuations and by strong mean vertical temperature gradients such as inversions (TATARSKII, 1961).

The instrument intercomparison (EMEIS et al., 2004) has shown that this SODAR can detect MLH quite well as long as it is within the vertical range of this instrument. The MLH has been detected from the SODAR data by employing two criteria. The first one diagnoses a sharp decrease of the acoustic backscatter intensity with height $\mathrm{z}$. The height $\mathrm{H}_{1}$ of this decrease usually indicates the top of a turbulent layer:

$$
\begin{gathered}
H_{1}=\quad z \text {, if }(R(z)<88 \mathrm{~dB} \text { and } R(z+1)<86 \mathrm{~dB} \\
\text { and } \quad R(z+2)<84 \mathrm{~dB}) .
\end{gathered}
$$

Here $\mathrm{R}(\mathrm{z})$ denotes the acoustic backscatter intensity in the height $\mathrm{z}$ above ground. The $\mathrm{dB}$ values are derived from an arbitrary scale because the received backscatter intensities cannot be calibrated. The $\mathrm{R}(\mathrm{z})$ values are specific for the SODAR used in this study, and they have been given for illustration purposes only. The second criterion looks for surface inversions and elevated inversions. It diagnoses (secondary) maxima of the backscatter intensity that are not related to high turbulence intensities. For elevated inversions we stipulate an increase in 
backscatter intensity below a certain height $\mathrm{z}=\mathrm{H}_{2}$ and a decrease above:

$$
\begin{aligned}
H_{2} & =\quad z, \text { if }(\partial R / \partial z(z+1)<0 \\
\text { and } & \left.R / \partial z(z-1)>0 \text { and } \sigma_{w}<0.70 \mathrm{~ms}^{-1}\right) .
\end{aligned}
$$

and for (usually nocturnal) surface inversions we demand:

$$
H_{2}=z, \text { if }\left(R(z)>105 \mathrm{~dB} \text { and } \sigma_{w}<0.3 \mathrm{~ms}^{-1}\right) .(2.3
$$

The restriction to low $\sigma_{w}$ values is necessary because high insolation leading to super-adiabatic temperature profiles near the ground also produces high backscatter intensities, but which are related with high turbulence intensities (high $\sigma_{w}$ ). The search for $\mathrm{H}_{1}$ and $\mathrm{H}_{2}$ is done separately. In both cases the search starts from below. If the criterion is fulfilled the search stops. If the search for $\mathrm{H}_{2}$ detects a surface inversion it stops, too, and does not look for further elevated inversions. The MLH is then defined:

$$
M L H=\min \left(H_{1}, H_{2}\right) \text {. }
$$

In case that neither $\mathrm{H}_{1}$ nor $\mathrm{H}_{2}$ is found MLH cannot be determined from the SODAR data. This happens e.g. during the afternoon of warm and sunny days when the CBL top is higher than the range of the SODAR. This does not necessarily mean that there is no inversion at all. More details can be found in TÜRK and EMEIS (2003).

\section{Data}

The data have been recorded in the vicinity of the street canyon "Göttinger Strasse" in the town of Hannover in Northern Germany. The town of Hannover has a radius of about 7 to $8 \mathrm{~km}$, the measurement site is to the southwest of the town centre about $3 \mathrm{~km}$ from the periphery of the town. The horizontally averaged roughness length of the area within a radius of $10 \mathrm{~km}$ is about $1 \mathrm{~m}$. In order to monitor the ambient flow conditions (wind profile and MLH) near this street canyon the SODAR has been placed about $550 \mathrm{~m}$ upstream of the street canyon on the grounds of a larger factory away from housing areas. This allowed an operation of the instrument without disturbing nearby inhabitants. From October 2001 until April 2003 the SODAR has been run with one and the same settings. Within each hour two half-hour means were recorded. The first one used a maximum range of $1160 \mathrm{~m}$ with a vertical resolution of $25 \mathrm{~m}$, the second one used half of this range with double vertical resolution $(12.5 \mathrm{~m})$. Both resolutions have been utilised for the evaluation described in (2.1) to (2.4). MLH determined from data with different resolution disagree by less than $10 \%$. For June and July 2002 no data are available because the instrument was operated in another place.

\section{Results}

The results will be presented for four selected months that are representative for the four seasons: April 2002 for spring, August 2002 for summer, November 2002 for autumn, and February 2003 for winter. Statistical analyses of the MLH time series have been performed. Here, we will show frequency distributions of MLH and mean daily courses of MLH in the different months. In the following we will discriminate between MLH statistics from equ. (2.4) and statistics for surface and elevated inversions $\left(\mathrm{H}_{2}\right)$ from equs. (2.2) and (2.3).

\subsection{Frequency distribution of MLH separated for day and night}

Fig. 1 shows the frequency distribution of half-hourly values of MLH from (2.4) for the four chosen months. The data have been separated for daytime (7 to 19 CET) and night-time (19 to 7 CET) conditions disregarding the seasons. This choice of an equal length for the daytime and the night-time period allows a direct intercomparison of the frequency distributions for the nightly hours and the daytime hours in all months. Please note that in Hannover CET is only 21 min ahead of the mean local time. We can identify three main regimes in the frequency distributions. In the lowest height bins (roughly below $200 \mathrm{~m}$ ) the frequency of nightly MLH is higher. Here, in this height range, surface inversions dominate. In the middle height bins (roughly from $200 \mathrm{~m}$ up to $600 \mathrm{~m}$ in February and November, up to $900 \mathrm{~m}$ in April, and up to $1200 \mathrm{~m}$ in August) the daytime MLH is more frequent. Here, convective influences dominate. In the upper range of height bins (with the exception of August) we find equal frequencies of nightly and daytime MLH due to very windy weather conditions. The rightmost columns give the frequency of half hours within which no MLH could be detected. A failure in MLH determination most frequently happens in April, August, and November, and is caused in most cases by thermal production of turbulence which leads to deep daytime convective boundary layers whose tops are out of range for the SODAR. In November stormy weather leads to such high MLH values.

In February 2003 (which was a cold winter month in Central Europe in 2003) the frequency of nightly MLH shows two maxima, one at $75 \mathrm{~m}$ and one around $325 \mathrm{~m}$. The first maximum is caused by low surface inversions in cold nights; the second maximum is due to two periods with a persistent elevated inversion between 250 and $450 \mathrm{~m}$ above ground. The latter of these two periods lasted for four days. For the daytime the frequency peak from these persistent elevated inversions merges with the frequency peak from days with some convection which caused MLH between 400 and $650 \mathrm{~m}$. In the 

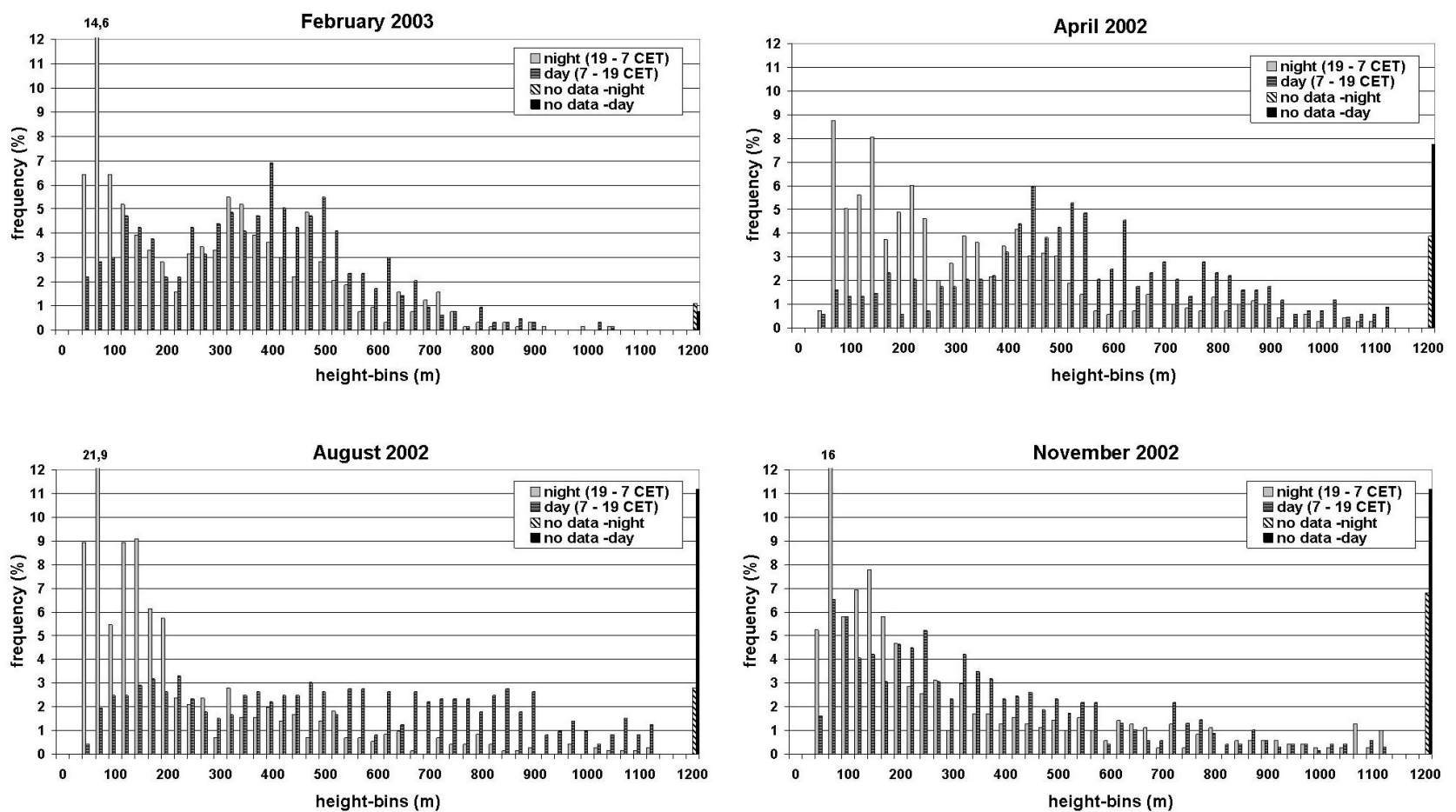

Figure 1: Frequency distribution of half-hourly values of MLH, computed from (2.4), in \%. Height bins are $25 \mathrm{~m}$ wide. The left column in each height bin is for night-time (19 to 7 CET); the right column is for daytime (7 to 19 CET). The columns in the height bin above $1200 \mathrm{~m}$ give the percentage of half hours in which no MLH could be detected. Small numbers on top of columns indicate true value if the column exceeds the frame of the image.
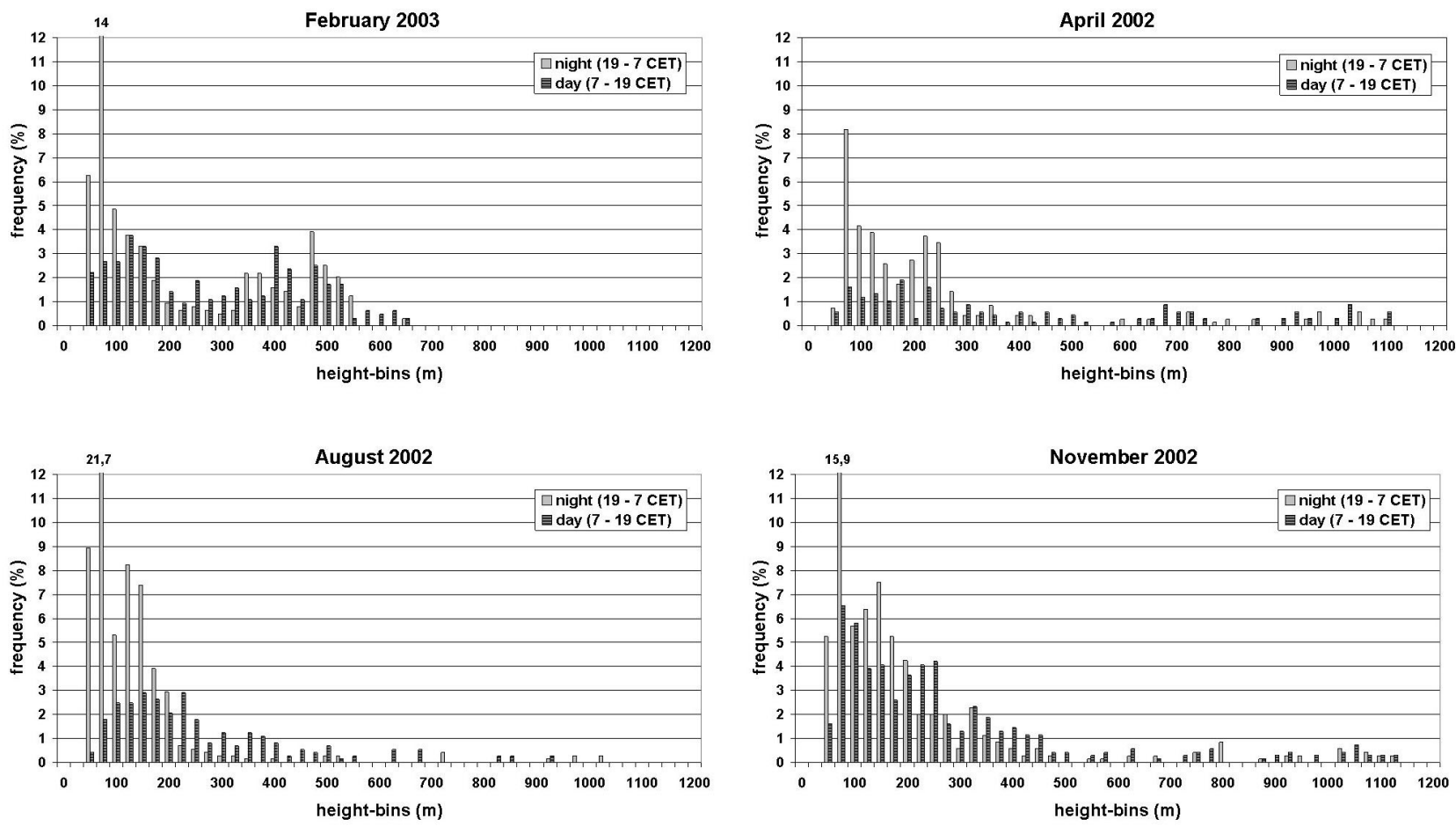

Figure 2: As Fig. 1, but for surface-based and elevated inversions only (computed from equs. (2.2) and (2.3)).

three other months no persistent elevated inversions oc- night-time frequency distribution. Due to a larger numcurred. Here, the surface-based inversions dominate the ber of days with the formation of a convective boundary 

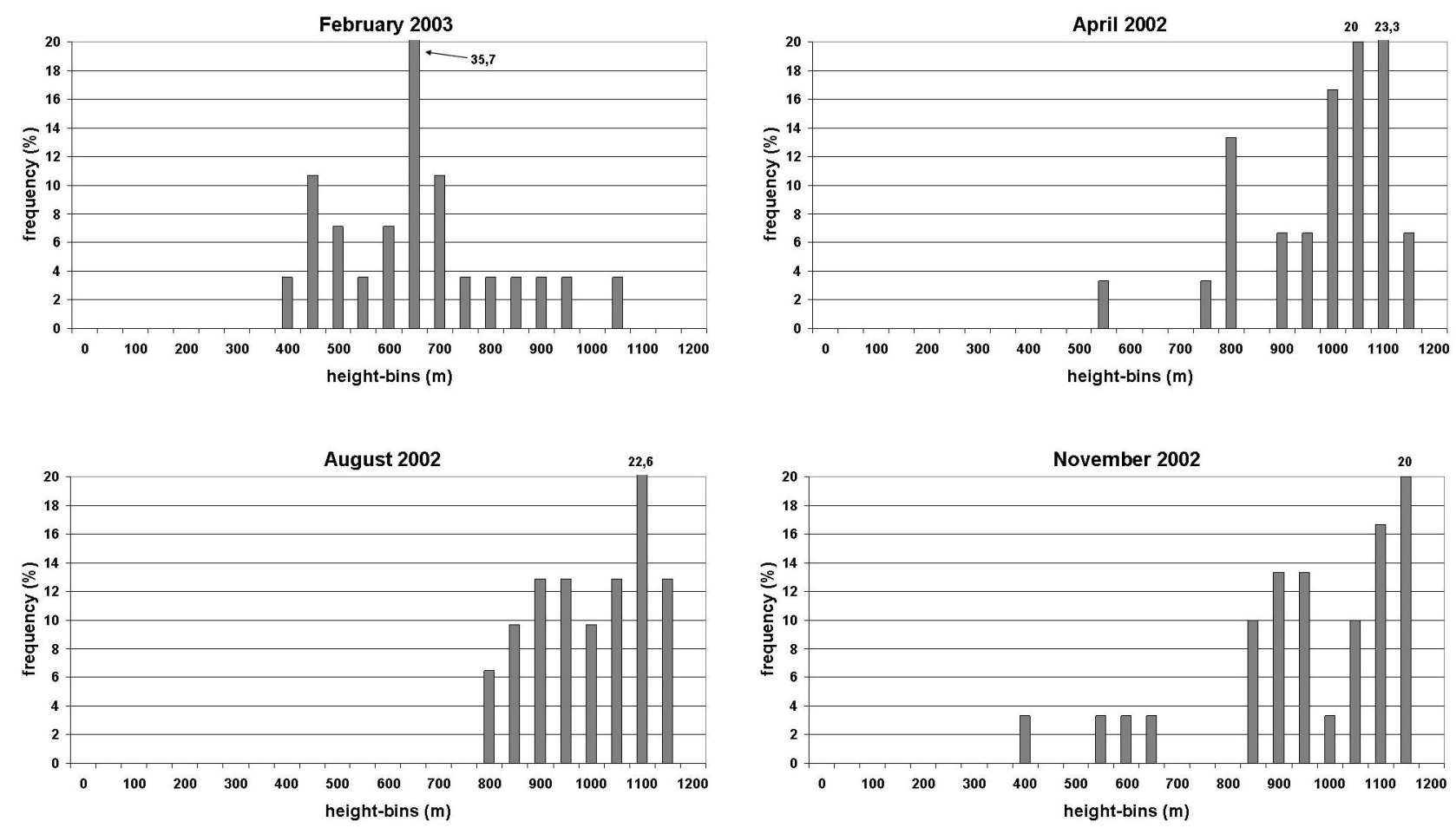

Figure 3: Frequency distribution of the daily maximum of MLH, computed from (2.4), in \%. The height bins are $50 \mathrm{~m}$ wide.
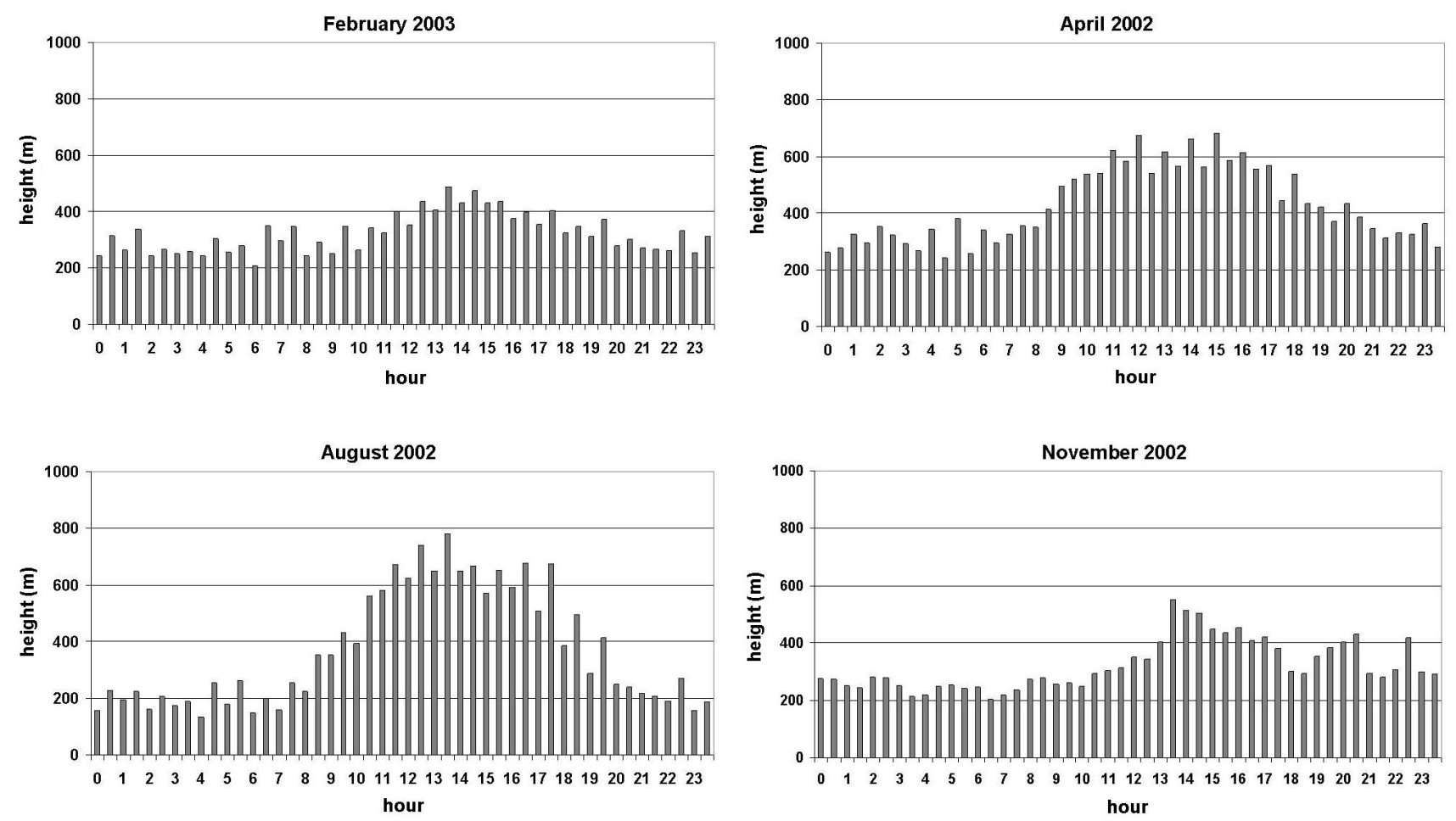

Figure 4: Mean daily course of MLH, computed from (2.4), in $\mathrm{m}$. The temporal resolution is one half hour.

layer in April and August the daytime frequency distribution is clearly shifted towards higher height bins compared to February and November. Due to the mostly mechanically produced turbulence in November the difference between the night-time and the daytime frequency distribution is smallest in this month.

\subsection{Frequency distribution of surface and elevated inversions separated for day and night}

Fig. 2 presents a subset of the data displayed in Fig. 1. Here only those MLH-values have been considered 
which were derived from equs. (2.2) and (2.3), i.e. those due to surface-based and elevated inversions. The frequency distributions are dominated by the night-time surface-based inversions in all four months. Only in the month of February a second peak is found due to the above mentioned persistent elevated inversions. In April in only $30 \%$ of all half hours an inversion height according to the criterion given in the equs. (2.2) and (2.3) is found. In the other months the fraction of surface-based and elevated inversions is higher (August: $46 \%$, February 2003: $50 \%$, and November: $61 \%$ ). The reason why is that in April the atmosphere is most unstable in the mean. The fraction of surface-based and elevated inversions increases with the mean stability of the air and low wind speeds. In the very stormy month February 2002 this fraction was only $22 \%$. The strong winds lead to strong mechanical mixing which destroys any inversion formed by night-time cooling very rapidly.

\subsection{Frequency distribution of the daily maximum of MLH separated for day and night}

In Fig. 3 the frequency distribution of the daily maximum of MLH (determined from equ. (2.4)) is plotted against height. Here, in contrast to Figs. 1 and 2, the height bins are $50 \mathrm{~m}$ wide. The lowest values appear in the winter month February, the highest in the summer month August. In August 2002, which was dominated by clear skies and high insolation, the daily maximum of MLH was never found below $800 \mathrm{~m}$.

\subsection{Mean daily course of MLH}

Finally, Fig. 4 shows the main daily course of the MLH (determined from equ. (4)) in all four months. The strongest diurnal variation is found in August 2002, the smallest diurnal amplitude is observed in November 2002. This is again caused by the amount of the incoming solar radiation which was highest in August (28 days with sunshine, among these were 19 days with more than four hours of sunshine). As February 2003 (22 days with sunshine, among these 12 with more than four hours of sunshine) and April 2002 (22 days with sunshine, 14 with more than four hours) also had a large number of sunny days they also exhibit a clear diurnal course but with smaller amplitude. November 2002 only had 15 days with some sunshine. Among these were only 6 days with more than four hours of sunshine. Dry air masses led to large differences between the daytime maximum temperature and the night-time minimum temperature in August 2002. This difference was regularly 10 degrees centigrade or even larger. In April 2002 this difference was only around 8 degrees. This strong diurnal course of near-surface temperatures led to the small MLH values in August 2002 at night-time. The MLH values are even lower than in April 2002.

\section{Discussion and outlook}

An automatic evaluation procedure in order to find the mixed-layer height (MLH) from SODAR data has been applied to 17 months of SODAR measurements within the town of Hannover in Northern Germany. The additional consideration of the variance of the vertical velocity component in contrast to earlier MLH determinations from SODAR data allowed the construction of a quite robust scheme. The main results are:

- It is possible to obtain long-term time series of MLH with a SODAR by an automated procedure.

- Three main regimes can be identified in the MLH statistics: low nocturnal MLH due to surface inversions, medium range daytime MLH values indicating the top of a convective boundary layer (CBL), and quite high MLH which appear with equal frequencies at day and at night due to very windy weather.

- Monthly frequency distributions of MLH and monthly mean daily courses of MLH show a clear annual course. Surface inversions are found in all seasons, CBL development was most notable in spring and summer from the mean daily course of MLH which had the greatest amplitude in these two seasons, and the windy weather was most pronounced in autumn.

- Specific meteorological characteristics of single months are distinctly mirrored in the MLH statistics. This shows that the interannual variability can be diagnosed from this data set, too.

This study proves the great advantages which lie in the application of remote sensing methods (in this case acoustic remote sensing with a large SODAR) for the investigation of the dynamic and thermal structure of the atmospheric boundary layer in heights which cannot continuously be reached by in-situ instruments.

\section{Acknowledgements}

The SODAR measurements were funded within the project VALIUM (Validation of instruments for environmental policies) of the German Ministry of Education and Research (BMBF) under the framework program AFO2000. The measurements would not have been possible without the technical and scientific support from the Niedersächsische Landesanstalt für Ökologie (NLÖ), Hannover, and METEK GmbH, Elmshorn. Special thanks go to Mr. DRUNKENMÖLLE from NLÖ. We thank Komatsu Germany GmbH for the permission to use their grounds for the SODAR measurements. The statistical evaluation of the MLH data was made by the second author while he was for a two-month practical training at the IMK-IFU in Garmisch-Partenkirchen. The training was financed by the Forschungszentrum Karlsruhe $\mathrm{GmbH}$ what we thankfully acknowledge. 


\section{References}

BEYRICH, F., 1997: Mixing height estimation from sodar data - a critical discussion. - Atmos. Environ. 31, 39413953.

BEYRICH, F., U. GÖRSDORF, 1995: Composing the diurnal cycle of mixing height from simultaneous SODAR and Wind profiler measurements. - Bound.-Layer Meteorol. 76, 387-394.

Coulter, R.L., 1979: A comparison of three methods for measuring mixing layer height. - J. Appl. Meteorol. 18, 1495-1499.

Dandou, A., E. Bossioli, M. Tombrou, N. Sifakis, D. Paronis, N. Soulakellis, D. Sarigiannis, 2002: The importance of mixing height in characterising pollution levels from aerosol optical thickness derived by satellite. Water, Air and Soil Poll.: Focus 2 (5-6), 17-28.

Devara, P.C.S., P. ERnest Ray, B.S. Murthy, G. PanDithurai, S. Sharma, K.G. Vernekar, 1995: Intercomparison of Nocturnal Lower-Atmospheric Structure Observed with LIDAR and SODAR Techniques at Pune, India. - J. Appl. Meteorol. 34, 1375-1383.

Emeis, S., Chr. Münkel, S. Vogt, W.J. Müller, K. SCHÄFER, 2004: Atmospheric boundary-layer structure from simultaneous SODAR, RASS, and ceilometer measurements. - Atmos. Environ. 38, 273-286.

Freedman, J.M., D.R. FitzJarRald, K.E. Moore AND R.K. SAKAI, 2001: Boundary Layer Clouds and Vegetation-Atmosphere Feedbacks. - J. Clim. 14, 180-197.

Holzworth, C.G., 1964: Estimates of mean maximum mixing depths in the contiguous United States. - Mon. Wea. Rev. 92, 235-242.

KEDER, J., 1999: Detection of Inversions and Mixing Height by REMTECH PA2 Sodar in Comparison with Collocated Radiosonde Measurements. - Meteorol. Atmos. Phys. 71, 133-138.

Lokoshchenko, M.A., 2002: Long-term Sodar Observations in Moscow and a New Approach to Potential Mixing
Determination by Radiosonde Data. - J. Atmos. Oceanic Technol. 19, 1151-1162.

Maughan, R.A., A.M. Spanton, M.L. Williams, 1982: An analysis of the frequency distribution of SODAR derived mixing heights classified by atmospheric stability. - Atmos. Environ. 16, 1209-1218.

Myrick, R.H., S.K. SAKIYAMA, R.P. Angle, H.S. SANDHU, 1994: Seasonal mixing heights and inversions at Edmonton, Alberta. - Atmos. Environ. 28, 723-729.

REITEBUCH, O., S. EMEIS, 1998: SODAR-measurements for atmospheric research and environmental monitoring. Meteorol. Z., N. F. 7, 11-14.

SAlcido, A., R. Sozzi, T. CASTro, 2003: Least squares variational approach to the convective mixing height estimation problem. - Environ. Mod. Softw. 18, 951-957.

SCHÄFER, K., G. FÖMmEl, H. HofFMANN, S. BRIZ, W. JunkermanN, S. EMEIS, C. JAHN, S. Leipold, A. Sedlmaier, S. Dinev, G. Reishofer, L. Windholz, N. Soulakellis, N. Sifakis and D. Sarigiannis, 2002: Three-Dimensional Ground-Based Measurements of Urban Air Quality to Evaluate Satellite Derived Interpretations for Urban Air Pollution. - Water, Air, and Soil Poll.: Focus 2 (5-6), 91-102.

Seibert, P., F. Beyrich, S.-E. Gryning, S. Joffre, A. RASMUSSEN, P. TERCIER, 2000: Review and intercomparison of operational methods for the determination of the mixing height. - Atmos. Environ. 34, 1001-1027.

TATARSKII, V.I., 1961: Wave propagation in a turbulent medium. - McGraw Hill, New York, 285 pp. (Englisch translation).

TÜRK, M., S. EMEIS, 2003: Bestimmung der Mischungsschichthöhe aus über einen Zeitraum von 16 Monaten durchgeführten SODAR-Messungen mittels automatischer Auswertung. - FZK-Bericht FZKA 6927. 30 pp. (in German). 